Document downloaded from:

http://hdl.handle.net/10251/64488

This paper must be cited as:

Cobacho Jordán, R.; Arregui De La Cruz, F.; Soriano Olivares, J.; Cabrera Rochera, E. (2015). Including leakage in network models: an application to calibrate leak valves in EPANET. Journal of Water Supply: Research and Technology - Aqua. 64(2):130-138. doi:10.2166/aqua.2014.197.

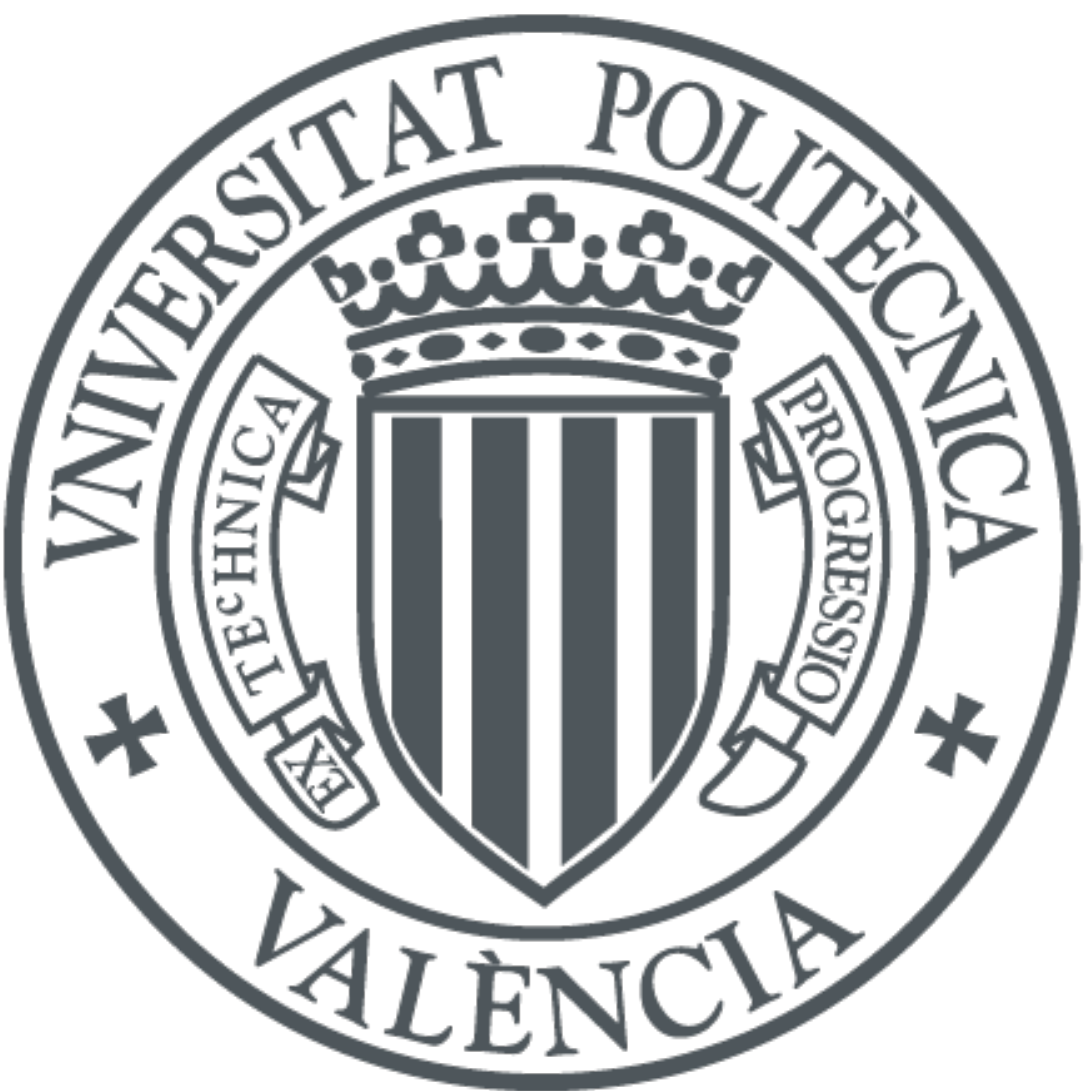

The final publication is available at

http://dx.doi.org/10.2166/aqua.2014.197

Copyright IWA Publishing

Additional Information 


\title{
Including leakage in network models: an application to calibrate leak valves in EPANET
}

\author{
Ricardo Cobacho, ${ }^{1}$ Francisco Arregui,,${ }^{1}$ Javier Soriano, ${ }^{1}$ Enrique Cabrera Jr. ${ }^{1}$ \\ ${ }^{1}$ Universitat Politècnica de València. ITA (building 5C, $1^{\text {st }}$ floor). 46022. Valencia. Spain \\ *Corresponding author, e-mail rcobacho@ita.upv.es
}

\begin{abstract}
EPANET is one of the most widely used software packages for water network hydraulic modelling, and is especially interesting for educational and research purposes because it is in the public domain. However, EPANET simulations are demand-driven, and the program does not include a specific functionality to model water leakage, which is pressure-driven. Consequently, users are required to deal with this drawback by themselves. As a general solution for this problem, this paper presents a methodology for including leakage in EPANET models by following a two-stage process. Firstly, leakage is spatially distributed among the nodes, according to the characteristics of the network. Secondly, leakage is modelled through an emitter at each node. The process is described in detail and two numerical examples illustrate the applicability and advantages of the method. In addition, free access through a URL is provided to the leakage modelling tool that has been developed.
\end{abstract}

KEYWORDS: water distribution networks; hydraulic modelling, leakage, EPANET, emitters.

\section{INTRODUCTION}

Hydraulic models of water distribution networks are tools which are commonly used today in the operation and management of water utilities. Running different sets of simulations on a network model may provide valuable outcomes to help managers make the right decisions. Such simulations and decisions can relate either to normal network operation or exceptional situations. Actions such as improving the design of new network enlargements, or assessing automatic valve settings fall into the first group; whereas foreseeing the hydraulic consequences of mains or pumping failures, or checking water supply capacity in the case of fire-fighting, fall into the second group. In addition, new applications continue to be developed. For example, network models have proven to be highly valuable in research on energy issues, such as the studies published by Boulos \& Bross (2010), and Cabrera et al. (2010).

The information needed to build a network model is clear. It basically includes knowledge of all the features of the system's physical assets, as well as the operational conditions of the dynamic elements. Information about water flows and consumption provided by the customer meter management system enables estimates of the magnitude and location of demand. Flow meters located at the network inlet points register the input water, and so total network water losses can be estimated through a water balance (Lambert \& Hirner, 2000). 
One software tool for water network modelling, which is widely used today, is EPANET (EPA, 2013). Apart from its calculation capabilities in daily network management, EPANET is of particular interest for university education and research purposes because it is publicdomain software. It has already enabled results to be successively achieved and published (Walski et al., 1995; Colombo \& Karney, 2002; Almandoz et al. 2005; Hernández et al. 2010; Arunkumar \& Mariappan, 2011; García et al. 2012; Ameyaw et al., 2013).

However, one of the main characteristics of EPANET is that its hydraulic calculation engine is demand-driven. The implication is that the data on water output at each node, defined as base demand, is input information that is needed to run each simulation. Flows in pipes and more importantly, pressures at nodes, are the simulation results. Under such formulation, there is no functionality to represent leakage in an explicit, straightforward, and reliable manner. Users must rely on their own knowledge and experience to overcome this drawback.

Classical works on hydraulic modelling (Germanopoulos, 1985; Germanopoulos \& Jowitt, 1989) have already published methods to include the pressure-dependent nature of water leakage in a hydraulic model:

$$
q_{i}=\beta_{i} L_{i} \bar{P}_{i}^{\alpha_{i}}
$$

where $q_{i}$ is the leakage of pipe $i, \beta_{i}$ is a leakage coefficient, $L_{i}$ is the length of the pipe, $\bar{P}_{i}$ is the average pressure of the pipe, and $\alpha_{i}$ is the leakage exponent. More recently, Giustolisi et al. (2008) developed a new algorithm to represent leakage more accurately by integrating the algorithm used by EPANET (Todini \& Pilati, 1988) with a pressure-driven model.

Other methods have been employed by professionals. The common characteristic among such methods is that leakage is modelled as an additional nodal demand. Total network leakage is determined based on the water balance and then distributed among the nodes. Hence, each node has at least two demands: consumption and leakage. A worthwhile improvement would be decoupling the leakage demand from the time-pattern ruling the consumption demand. Leakage demand could remain as a steady value, or better, it could be assigned a specific leakage time-pattern obtained from the network operation records. However, the main problem is still that leakage flow is modelled as a fixed and independent quantity, although it is a variable and pressure-dependent parameter.

\section{METHOD PROPOSED}

In the authors' opinion, the best way to represent leakage in a hydraulic network model is not by means of an additional demand, but rather by adding a leak valve to each node $j$, as illustrated in Figure 1, where $Q_{B D j}$ is the node base demand (consumption), $P_{j}$ is the node pressure, $K_{j}$ is the leak valve coefficient and $Q_{j}$ is the leakage flow. Under this representation, the pressure at the node behaves as the leakage driving factor, and the flow leaked through the valve may be estimated accordingly (Al-Ghamdi, 2011). 


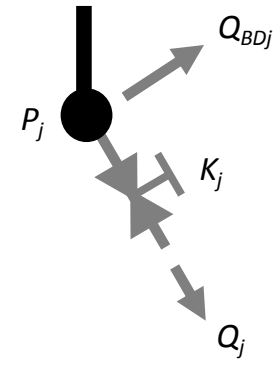

Figure 1. Scheme of a node leak valve

When using EPANET for leakage modelling, the element the most closely resembling a leak valve is the emitter, which presents an open valve to the atmosphere. Unlike a standard EPANET valve which is a link between two nodes, the emitter is a simple node element. Therefore, using emitters does not needlessly increase the model complexity with additional new nodes. The emitter behaviour equation is very simple:

$$
Q_{j}=K_{j} P_{j}^{N}
$$

where $Q_{j}$ is the leakage flow rate at node $j, P_{j}$ is the pressure, $K_{j}$ is the emitter coefficient, and $N$ is the pressure exponent. This equation is consistent with the FAVAD theory (May, 1994; Thornton \& Lambert, 2005; Cassa \& van Zyl, 2013), where the pressure exponent mainly depends on the predominant pipe material $(0.5$ for metallic pipes, 1.2 or greater for plastic pipes, and about 1.0 for different materials more or less equally combined).

In summary, the new approach begins by estimating the total network water losses, and then a two-stage method is used to model leakage. In the first stage, the spatial distribution of leakage is determined. In the second stage, the leakage is distributed among the nodes by calibrating the emitter parameters. The results are verified to ensure that the total amount of water leaked in the model is equal to that of the real network. A detailed description of the process is presented below.

\section{Stage 1 - Spatial distribution of leakage}

The spatial distribution of leakage depends on the particular features and conditions of each network. Water leakage occurs physically in pipes. Therefore, each pipe needs first to be characterised according to the factors that influence leakage. Unlike the direct physical model (Equation 1) used by Germanopoulos (1985) and Giustolisi et al. (2008), the authors propose to characterise such influences in a more flexible way: each factor affecting pipe leakage is represented by a leak variable $(\gamma)$, not a pressure coefficient; and each pipe $i$ in the model is characterised by a particular leak variable value $\left(\gamma_{i}\right)$.

Assuming that leakage is uniformly distributed along each pipe (Germanopoulos, 1985), then each $\gamma_{i}$ will be equally divided between both pipe nodes. All the half $\gamma_{i}$ 's are then assigned to every node $j$ from the pipes it connects, i.e.,

$$
\gamma_{j}=\sum_{i=1}^{m_{j}} \gamma_{i}
$$

where $m_{j}$ is the number of pipes connected to node $j$. Finally, each $\gamma_{j}$ is normalised by: 


$$
\Gamma_{j}=\frac{\gamma_{j}}{\sum \gamma_{i}}=\frac{\gamma_{j}}{\gamma_{N e t}}
$$

where $\gamma_{\text {Net }}$ is the total sum of all $\gamma_{i}$. The $\Gamma_{j}$ thus obtained represents the relative importance of each node in terms of leakage, as compared to the whole of the network.

In simple cases, e.g., a small network whose pipes are homogeneous, $\gamma$ could be just the pipe length. In networks that are not so homogeneous, the number of repairs per pipe length could be used in combination with the pipe length. It is a simple indicator that may include both reported breaks and unreported leaks (located through active leakage control). In cases where the available network maintenance records are sufficiently large and accurate, a more complex alternative consists in fitting the number of repairs per length in recent years to an exponential expression (Shamir \& Howard, 1979; Kleiner \& Rajani, 2002). Such an expression would provide the number of failures in recent years for each pipe or group of pipes, and this number could be considered, in combination with pipe length, as the leak variable for the purpose of distributing leakage.

In more complex cases, other additional factors may be considered - such as diameters (Walski \& Pelliccia, 1982); age (Berardi et al., 2005); service connections (Lambert \& Hirner, 2000); and material, soil, and water pressure (Kleiner \& Rajani, 2002). Therefore, the modeller may consider one leak variable $\gamma_{k}$ per factor $k$ and assign each to the pipes $\left(\gamma_{k, i}\right)$ and nodes $\left(\gamma_{k, j}\right)$ accordingly. The normalised values may then be calculated for each node $\left(\Gamma_{k, j}\right)$ and, finally, they may be combined to obtain the lumped nodal value $\Gamma_{j}$. This whole process is considered a multi-criteria decision problem and may require one of the available techniques, e.g., weighted sum model (Triantaphyllou, 2002); analytical hierarchical process (Cabrera et al., 2011); fuzzy logic (Islam et al., 2012; Parra et al., 2013; Cavallo et al., 2013), etc.

\section{Stage 2 - Calibration of emitter coefficients at network nodes}

The second stage of the methodology consists in calibrating all the leak valve coefficients (Equation 2) through an iterative process. One initial step consists in calculating a leakage coefficient for the whole network to be used in the first iteration:

$$
K_{N e t}^{(1)}=\frac{Q_{N e t, r e a l}}{\bar{P}_{N e t}}
$$

where $Q_{\text {Net,real }}$ is the real total network leakage over a period of $24 \mathrm{~h}, \bar{P}_{\text {Net }}$ is the average pressure of the nodes, and $N$ is the pressure exponent. The second step is to distribute the network leakage coefficient among the nodes using the expression:

$$
K_{j}^{(h)}=K_{N e t}^{(h)} \Gamma_{j}
$$

where $K_{j}^{(h)}$ is the leak valve coefficient at node $j$ in iteration $h, K_{N e t}^{(h)}$ is the network leakage coefficient in iteration $h$, and $\Gamma_{j}$ is the normalised leak variable value for node $j$. 
The third step consists in simulating the network with the estimated emitter coefficients over a 24-h period. The final step is to calculate the simulated total network leakage $\left(Q_{N e t, \text { model }}^{(h)}\right)$ and compare it to the known real total network leakage $\left(Q_{N e t, r e a l}\right)$.

$$
\left|Q_{N e t, \text { model }}^{(h)}-Q_{N e t, r e a l}\right| \leq \varepsilon
$$

where 0.005 is suggested as a general value for $\varepsilon$. Depending on the difference $\mid Q_{\text {Net,model }}^{(h)}$ $Q_{N e t, r e a l} \mid$, the network leakage coefficient for the next iteration $\left(K_{N e t}^{(h+1)}\right)$ is modified accordingly, and the sequence is repeated, from the second step on, until the convergence criteria is satisfied. An illustration of the iterative process is presented in Figure 2.

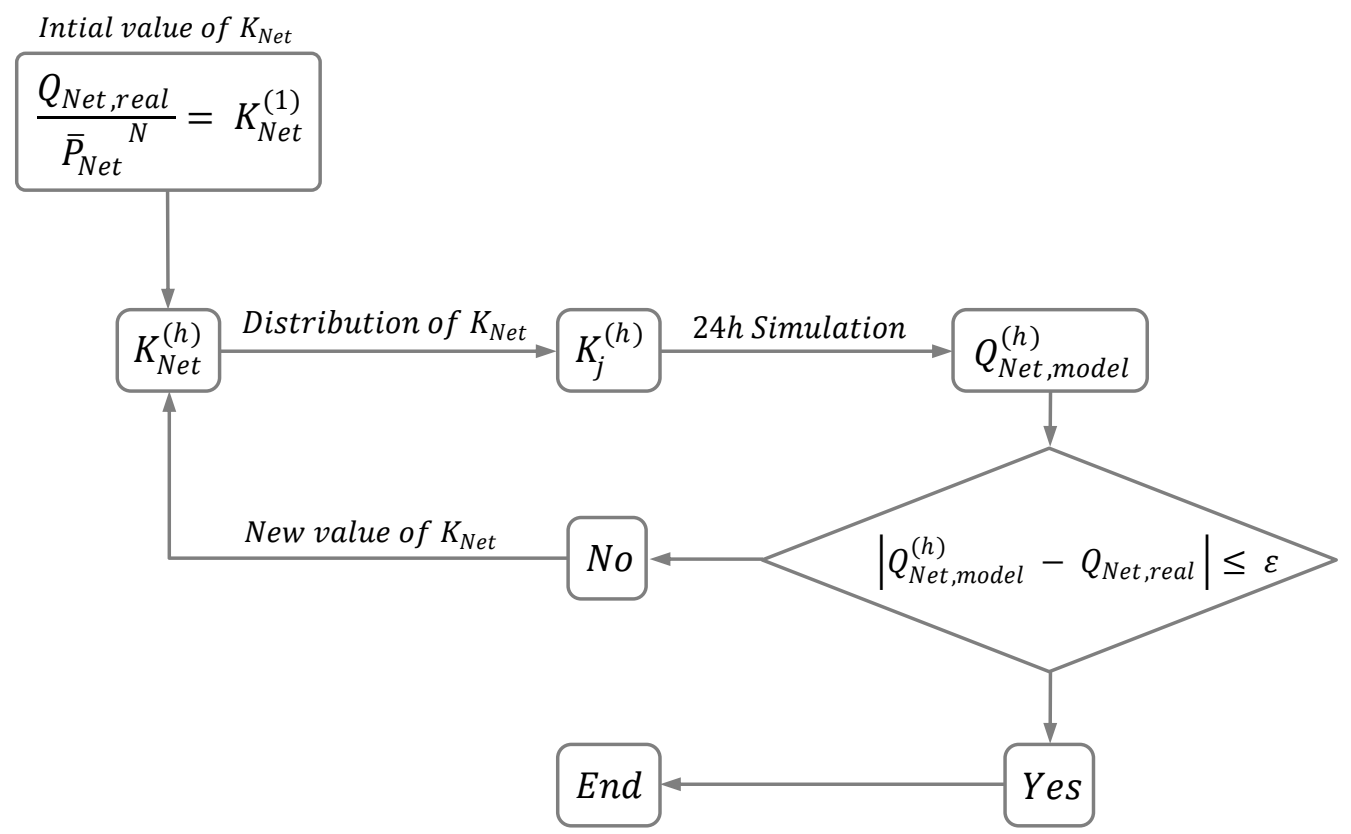

Figure 2. Iterative process to tune $K_{\text {Net }}$ value

\section{NUMERICAL EXAMPLE 1 - USING EMITTERS}

The network illustrated in Figure 3 supplies water to 25,000 people through 8,000 service connections. Table 1 shows the network characteristics. All pipes have a roughness of $0.1 \mathrm{~mm}$. The total network water inflow is $5,100 \mathrm{~m}^{3} /$ day $(59.01 \mathrm{~L} / \mathrm{s})$. Meters at the consumer sites enable calculating base demand and daily consumption patterns for each node (Table 1 and Table 2); the total water demand computed through aggregation is $3,500 \mathrm{~m}^{3} /$ day $(40.5$ $\mathrm{L} / \mathrm{s})$. The total leakage estimate is $1,600 \mathrm{~m}^{3} /$ day $(18.5 \mathrm{~L} / \mathrm{s})$ and is calculated using a simplified water balance (network input $=$ consumption + leakage); therefore, the average water efficiency is $68.5 \%$. There is a fairly balanced combination of pipe materials in the network and so the pressure exponent is assumed to equal 1.1. The network pressure is about $40 \mathrm{~m}$ on average and about $15 \mathrm{~m}$ during peak demand time. 


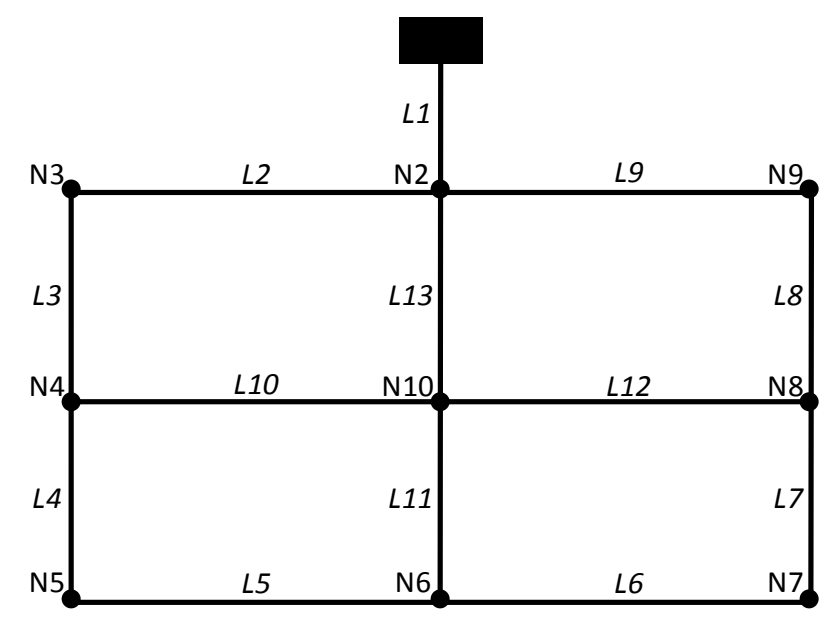

Figure 3. Example water network

\begin{tabular}{|ccc|cccc|}
\hline $\begin{array}{c}\text { Pipe } \\
\text { ID }\end{array}$ & $\begin{array}{c}\text { Length } \\
\mathbf{( m )}\end{array}$ & $\begin{array}{c}\text { Diameter } \\
\mathbf{( m m})\end{array}$ & Node ID & $\begin{array}{c}\text { Elevation } \\
\mathbf{( m )}\end{array}$ & $\begin{array}{c}\text { Consumption } \\
\mathbf{( L / s )}\end{array}$ & $\begin{array}{c}\text { Time } \\
\text { Pattern } \\
\text { ID }\end{array}$ \\
\hline L1 & 6,250 & 300 & N2 & 55 & 1.1 & PatA \\
\hline L2 & 3,100 & 200 & N3 & 27 & 4.0 & PatB \\
\hline L3 & 1,800 & 200 & N4 & 25 & 3.4 & PatC \\
\hline L4 & 3,800 & 200 & N5 & 12 & 3.4 & PatA \\
\hline L5 & 3,700 & 80 & N6 & 3 & 4.5 & PatD \\
\hline L6 & 2,200 & 100 & N7 & 12 & 5.6 & PatA \\
\hline L7 & 1,600 & 150 & N8 & 23 & 3.4 & PatC \\
\hline L8 & 4,600 & 150 & N9 & 12 & 5.0 & PatD \\
\hline L9 & 1,400 & 150 & N10 & 32 & 3.4 & PatE \\
\hline L10 & 2,600 & 100 & & & & \\
\hline L11 & 3,600 & 80 & Reservoir & 100 & & \\
\hline L12 & 1,500 & 200 & & & & \\
\hline L13 & 3,800 & 250 & & & & \\
\hline
\end{tabular}

Table 1. Nodes and pipes

To illustrate the application of the method, leakage was modelled in two different ways, which were then compared. Model M1 is obtained by assuming the total network leakage $(18.5 \mathrm{~L} / \mathrm{s})$ as an additional steady demand at each node $(2.055 \mathrm{~L} / \mathrm{s})$ with no time pattern. Model M2 introduces leakage using the proposed method.

Two numerical examples are provided below. In this first example, attention is only focused on the procedure for emitter calibration, and the only criterion considered for the spatial distribution of leakage is pipe length. Consequently, the value for $\gamma_{i}$ for each pipe is simply the pipe length in meters. Table 3 shows the $\gamma_{j}$ for each node, as well as the resulting $\Gamma_{j}$. 

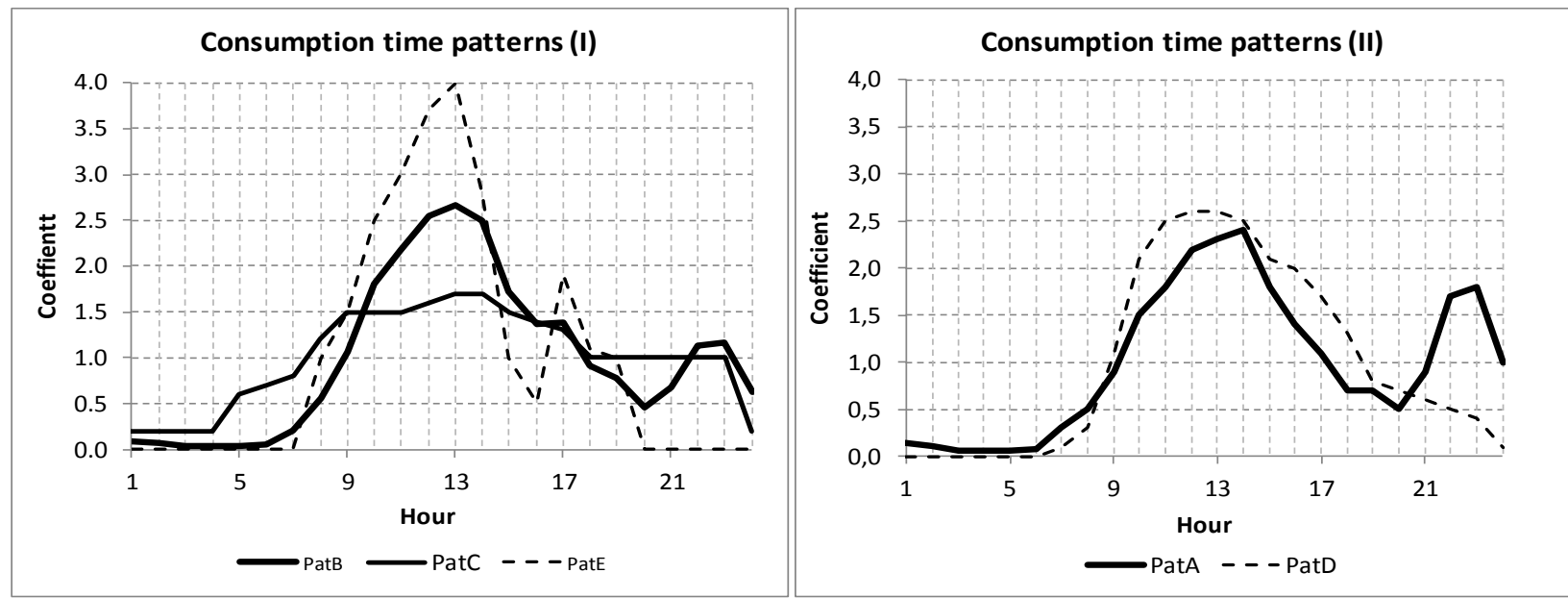

Figure 4. Node consumption time pattern values

\begin{tabular}{|ccccccccccccccccccccccccc}
\hline Hour & $\mathbf{1}$ & $\mathbf{2}$ & $\mathbf{3}$ & $\mathbf{4}$ & $\mathbf{5}$ & $\mathbf{6}$ & $\mathbf{7}$ & $\mathbf{8}$ & $\mathbf{9}$ & $\mathbf{1 0}$ & $\mathbf{1 1}$ & $\mathbf{1 2}$ & $\mathbf{1 3}$ & $\mathbf{1 4}$ & $\mathbf{1 5}$ & $\mathbf{1 6}$ & $\mathbf{1 7}$ & $\mathbf{1 8}$ & $\mathbf{1 9}$ & $\mathbf{2 0}$ & $\mathbf{2 1}$ & $\mathbf{2 2}$ & $\mathbf{2 3}$ & $\mathbf{2 4}$ \\
\hline PatA & 0.14 & 0.11 & 0.06 & 0.06 & 0.06 & 0.07 & 0.30 & 0.50 & 0.90 & 1.50 & 1.80 & 2.20 & 2.30 & 2.40 & 1.80 & 1.40 & 1.10 & 0.70 & 0.70 & 0.50 & 0.90 & 1.70 & 1.80 & 1.00 \\
PatB & 0.08 & 0.07 & 0.04 & 0.04 & 0.04 & 0.05 & 0.21 & 0.55 & 1.06 & 1.81 & 2.17 & 2.55 & 2.67 & 2.49 & 1.72 & 1.37 & 1.38 & 0.91 & 0.78 & 0.46 & 0.67 & 1.13 & 1.16 & 0.62 \\
PatC & 0.2 & 0.2 & 0.2 & 0.2 & 0.6 & 0.7 & 0.8 & 1.2 & 1.5 & 1.5 & 1.5 & 1.6 & 1.7 & 1.7 & 1.5 & 1.4 & 1.3 & 1.0 & 1.0 & 1.0 & 1.0 & 1.0 & 1.0 & 0.2 \\
\hline PatD & 0.0 & 0.0 & 0.0 & 0.0 & 0.0 & 0.0 & 0.1 & 0.3 & 1.1 & 2.1 & 2.5 & 2.6 & 2.6 & 2.5 & 2.1 & 2.0 & 1.7 & 1.3 & 0.8 & 0.7 & 0.6 & 0.5 & 0.4 & 0.1 \\
PatE & 0.0 & 0.0 & 0.0 & 0.0 & 0.0 & 0.0 & 0.0 & 1.0 & 1.5 & 2.5 & 3.0 & 3.7 & 4.0 & 2.8 & 1.0 & 0.5 & 1.9 & 1.1 & 1.0 & 0.0 & 0.0 & 0.0 & 0.0 & 0.0 \\
\hline
\end{tabular}

Table 2. Node consumption time pattern values

Considering the average network pressure of $40 \mathrm{~m}, K_{N e t}$ has an initial value of $K_{N e t}^{(1)}=18.5 /(40)^{1.1}=0.319$. The first value for each emitter coefficient $\left(K_{j}^{(1)}\right)$ is shown in Table 3. After the iterative process (nine iterations in this case), the final values were obtained for the emitter coefficients $\left(K_{j}^{(9)}\right)$ as presented in Table 3.

\begin{tabular}{|c|c|c|c|c|c|c|}
\hline $\begin{array}{l}\text { Node } \\
\text { ID }\end{array}$ & $\begin{array}{c}\text { Length }(\mathrm{m}) \\
\gamma_{j}\end{array}$ & $\Gamma_{j}$ & $\begin{array}{c}K_{\text {Net }}^{(1)} \\
(\mathrm{L} / \mathrm{s}) /(\mathrm{m})^{1.1}\end{array}$ & $\begin{array}{c}K_{j}^{(1)} \\
(\mathrm{L} / \mathrm{s}) /(\mathrm{m})^{1.1}\end{array}$ & $\begin{array}{c}K_{\text {Net }}^{(9)} \\
(\mathrm{L} / \mathrm{s}) /(\mathrm{m})^{1.1}\end{array}$ & $\begin{array}{c}K_{j}^{(9)} \\
(\mathrm{L} / \mathrm{s}) /(\mathrm{m})^{1.1}\end{array}$ \\
\hline N2 & 10,400 & 0.260 & 0.319 & 0.239 & 0.249 & 0.065 \\
\hline N3 & 2,450 & 0.061 & 0.319 & 0.056 & 0.249 & 0.015 \\
\hline N4 & 4,100 & 0.103 & 0.319 & 0.094 & 0.249 & 0.026 \\
\hline N5 & 3,750 & 0.094 & 0.319 & 0.086 & 0.249 & 0.023 \\
\hline N6 & 4,750 & 0.119 & 0.319 & 0.109 & 0.249 & 0.030 \\
\hline N7 & 1,900 & 0.048 & 0.319 & 0.044 & 0.249 & 0.012 \\
\hline N8 & 3,850 & 0.096 & 0.319 & 0.089 & 0.249 & 0.024 \\
\hline N9 & 3,000 & 0.075 & 0.319 & 0.069 & 0.249 & 0.019 \\
\hline N10 & 5,750 & 0.144 & 0.319 & 0.132 & 0.249 & 0.036 \\
\hline
\end{tabular}

Table 3. Initial emitter $K_{j}$ values for first and last iteration 


\section{Model results comparison under usual operating conditions}

One of the key variables to assess the validity of a hydraulic model is the network pressure after a simulation. Table 4 shows nodal pressures for low, mean, and peak consumption hours. However, as consumption increased from 9:00 to 13:00 the differences became wider, and eventually, unacceptable negative values were obtained at 13:00 with M1. Pressure results provided by M2 stay positive at that time and sufficiently close to the average $15 \mathrm{~m}$ pressure level.

\begin{tabular}{|c|cc|cc|cc|}
\hline Node & $\mathbf{M 1}$ & $\mathbf{M 2}$ & $\mathbf{M 1}$ & $\mathbf{M 2}$ & $\mathbf{M 1}$ & $\mathbf{M 2}$ \\
& $\mathbf{9 : 0 0}$ & $\mathbf{9 : 0 0}$ & $\mathbf{1 1 : 0 0}$ & $\mathbf{1 1 : 0 0}$ & $\mathbf{1 3 : 0 0}$ & $\mathbf{1 3 : 0 0}$ \\
\hline N2 & 29.9 & 30.0 & 8.0 & 14.3 & -1.1 & 6.3 \\
\hline N3 & 50.0 & 50.5 & 17.2 & 26.8 & 2.7 & 13.8 \\
\hline N4 & 49.6 & 50.0 & 13.7 & 24.1 & -2.3 & 9.7 \\
\hline N5 & 59.5 & 59.7 & 16.8 & 28.3 & -2.7 & 10.4 \\
\hline N6 & 65.4 & 64.3 & 13.0 & 26.3 & -4.6 & 12.1 \\
\hline N7 & 62.5 & 63.0 & 23.9 & 34.8 & 8.1 & 20.7 \\
\hline N8 & 55.9 & 56.0 & 25.7 & 34.3 & 13.3 & 23.3 \\
\hline N9 & 68.7 & 68.8 & 39.5 & 47.4 & 28.5 & 37.7 \\
\hline N10 & 48.5 & 48.5 & 20.2 & 28.2 & 8.4 & 17.6 \\
\hline
\end{tabular}

Table 4. Comparison of node pressures in models M1 and M2

As water consumption (average and time pattern) and water losses (average) are the same in both models, the only reason that explains the worse performance of M1 is the time evolution of water leakage. Figure 5 shows the time evolution of water flows in both models. The dynamic behaviour of leakage is clearly appreciated in the case of M2. In contrast, the constant leakage flow rate of M1 is the cause of higher values of flow rates in the network at peak time, and the resulting negative pressure values were obtained.
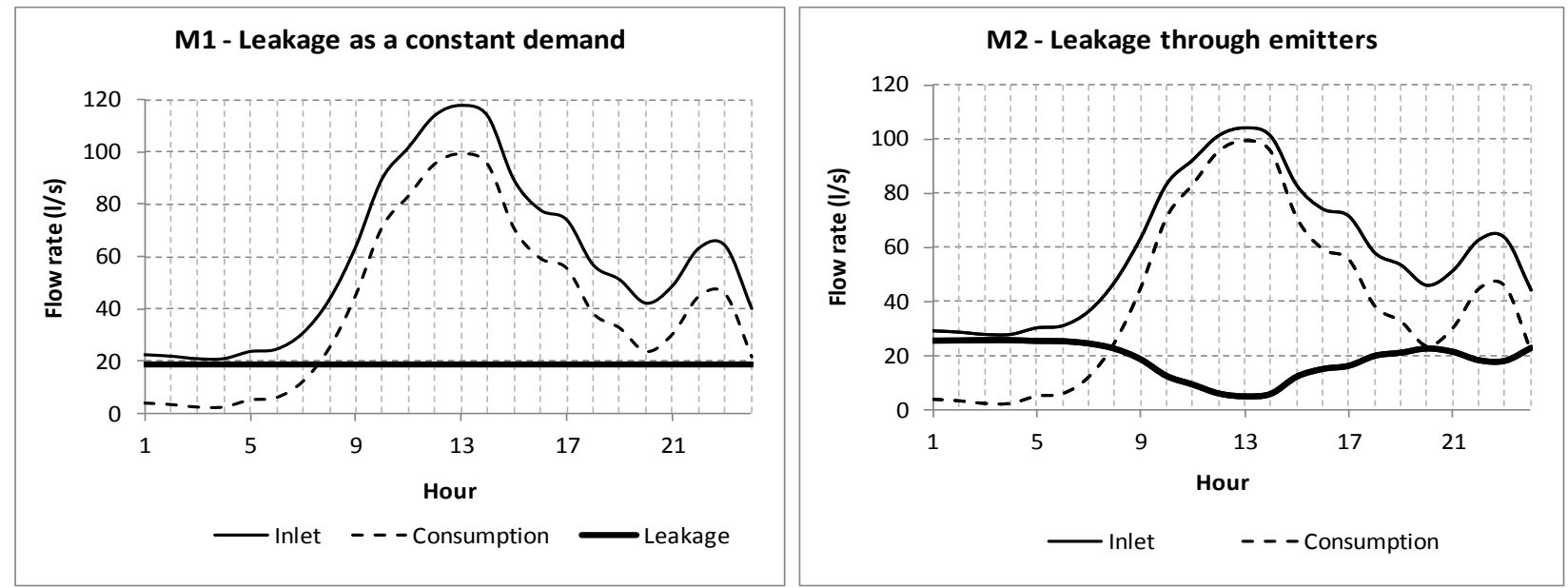

Figure 5. Inlet water comparison between models M1 and M2 
At this stage, M1 would require further improvements to overcome the negative pressure problem. Such improvements would possibly consist in using an artificial time pattern that represents the leakage variation. Conversely, the calibrated emitters in M2 have already solved the problem in a consistent way, either in terms of hydraulic behaviour or welladjusted water balance. If further calibration was required for M2, it would be quicker and more straightforward to implement than the calibration required for M1.

\section{Model results comparison under an unusual operating condition}

Unusual operating conditions could be difficult to foresee, and when simulated, they may make models produce results that are not always valid. Single pipe closing was tested for M1 and M2. A 24-hour simulation was performed after closing each single pipe of the network. Assuming that water consumption is unaffected by the consequences of such closings, node pressures after the simulations were examined in search of a negative value at any hour. The results are summarised in Table 5 as the number of nodes with negative pressure values after each pipe shut-off. If that number is greater than zero, the model does not pass the pipeclosing test. The conclusion is that M2 is sufficiently robust for up to four pipes in the pipe closing test (L9, L10, L8 and L5), whereas M1 fails in all cases.

\begin{tabular}{ccc}
\hline Pipe & M1 & M2 \\
\hline L4 & 17 & 17 \\
\hline L2 & 17 & 13 \\
L7 & 14 & 12 \\
\hline L3 & 13 & 11 \\
\hline L13 & 8 & 6 \\
\hline L12 & 7 & 4 \\
\hline L6 & 7 & 4 \\
\hline L11 & 3 & 1 \\
\hline L9 & 4 & 0 \\
\hline L10 & 3 & 0 \\
\hline L8 & 3 & 0 \\
\hline L5 & 3 & 0 \\
\hline
\end{tabular}

Table 5. Number of hours for which negative pressures are obtained after closing a pipe

\section{NUMERICAL EXAMPLE 2 - SPATIAL DISTRIBUTION OF LEAKAGE}

To illustrate the procedure for the spatial distribution of leakage, the network information was enhanced. In addition to pipe length, the number of service connections and failures were considered as leakage factors in the analysis.

Table 6 shows the values of the coefficients $\gamma_{k, i}$ which were assigned to each leakage factor and pipe. While the number of service connections has simple direct coefficient values, the number of failures per year was considered in a more comprehensive way. The reason is that an oversimplification, such as taking only the number of failures in the past year, may lead to biased results due to particular circumstances that may have occurred during such a year. In this example, we use an exponential model representing the relationship between number of 
failures per km-year and age in years (Shamir \& Howard, 1979; Kleiner \& Rajani, 2002). We assume the availability of historical records to construct three equations corresponding to pipes grouped by age. The values obtained from the equations are multiplied by pipe length to obtain the leakage coefficient for failures.

\begin{tabular}{|c|c|c|c|c|c|c|}
\hline Pipe & $\begin{array}{c}\text { Length (m) } \\
\gamma_{1, i} \\
\end{array}$ & $\begin{array}{c}\text { Serv. Con. } \\
\gamma_{2, i}\end{array}$ & $\begin{array}{c}\begin{array}{c}\text { Age } \\
\text { (years) }\end{array} \\
\end{array}$ & $\begin{array}{c}\text { Fail. Equation } \\
\text { (Fail./(km·year)) }\end{array}$ & $\begin{array}{c}\text { Fail./ } \\
\text { (km·year) }\end{array}$ & $\begin{array}{c}\text { Fail./year } \\
\gamma_{3, i}\end{array}$ \\
\hline L1 & 6,250 & 460 & 40 & \multirow{5}{*}{$0.15 e^{0.081 t}$} & 3.83 & 23.9 \\
\hline L2 & 3,100 & 1200 & 40 & & 3.83 & 11.9 \\
\hline L3 & 1,800 & 900 & 35 & & 2.55 & 4.6 \\
\hline L10 & 2,600 & 950 & 35 & & 2.55 & 6.6 \\
\hline L13 & 3,800 & 900 & 35 & & 2.55 & 9.7 \\
\hline L4 & 3,800 & 540 & 20 & \multirow{4}{*}{$0.29 e^{0.063 t}$} & 1.02 & 3.9 \\
\hline L5 & 3,700 & 500 & 20 & & 1.02 & 3.8 \\
\hline L9 & 1,400 & 500 & 20 & & 1.02 & 1.4 \\
\hline L11 & 3,600 & 500 & 20 & & 1.02 & 3.7 \\
\hline L8 & 4,600 & 550 & 10 & \multirow{4}{*}{$0.21 e^{0.048 t}$} & 0.34 & 1.6 \\
\hline L12 & 1,500 & 550 & 10 & & 0.34 & 0.5 \\
\hline L6 & 2,200 & 330 & 5 & & 0.27 & 0.6 \\
\hline L7 & 1,600 & 120 & 5 & & 0.27 & 0.4 \\
\hline
\end{tabular}

Table 6. Pipe characteristics considered for spatial distribution of leakage

Table 7 shows the results of the spatial distribution of leakage to the network nodes. The three leakage factors were considered of equal importance, hence the final combined coefficient $\Gamma_{j}$ was obtained by a simple average. The coefficient represents each node's spatial incidence in terms of leakage. Finally, emitter coefficients $K_{j}$ were obtained, after an iterative process (six iterations) as described above. Differences can be easily noticed between those $K_{j}$ which were based on three criteria and previous examples (Table 3) that were based on only one criterion. However, as the network is simplified, the aim of the second example is not to decide whether to consider more criteria or not, but to illustrate the application of the method when more infrastructure data is available.

\begin{tabular}{|c|cc|cc|cc|c|cc|}
\hline Node & $\begin{array}{c}\text { Length } \\
(\mathbf{m}) \\
\gamma_{1, j}\end{array}$ & $\boldsymbol{\Gamma}_{1, j}$ & $\begin{array}{c}\text { Serv. } \\
\text { Con. } \\
\gamma_{2, j}\end{array}$ & $\boldsymbol{\Gamma}_{2, j}$ & $\begin{array}{c}\text { Fail./ } \\
\text { year } \\
\gamma_{3, j}\end{array}$ & $\boldsymbol{\Gamma}_{3, j}$ & $\boldsymbol{\Gamma}_{j}$ & $\begin{array}{c}\boldsymbol{K}_{\text {Net }}{ }^{(6)} \\
(\mathbf{L} / \mathbf{s}) /(\mathbf{m})^{1.1}\end{array}$ & $\begin{array}{c}\boldsymbol{K}_{j}^{(6)} \\
(\mathbf{L} / \mathbf{s}) /(\mathbf{m})^{1.1}\end{array}$ \\
\hline N2 & 10,400 & 0.261 & 1,370 & 0.171 & 31.9 & 0.439 & 0.290 & 0.238 & 0.069 \\
N3 & 2,450 & 0.061 & 1,050 & 0.131 & 8.2 & 0.113 & 0.102 & 0.238 & 0.024 \\
N4 & 4,100 & 0.103 & 1,200 & 0.150 & 6.4 & 0.088 & 0.114 & 0.238 & 0.027 \\
N5 & 3,750 & 0.094 & 925 & 0.116 & 8.2 & 0.113 & 0.107 & 0.238 & 0.025 \\
N6 & 4,750 & 0.119 & 995 & 0.124 & 7.1 & 0.097 & 0.113 & 0.238 & 0.027 \\
N7 & 1,900 & 0.048 & 520 & 0.065 & 3.8 & 0.053 & 0.055 & 0.238 & 0.013 \\
N8 & 3,850 & 0.096 & 665 & 0.083 & 2.9 & 0.040 & 0.073 & 0.238 & 0.017 \\
\hline N9 & 3,000 & 0.075 & 500 & 0.063 & 2.6 & 0.035 & 0.058 & 0.238 & 0.014 \\
N10 & 5,750 & 0.144 & 775 & 0.097 & 1.5 & 0.021 & 0.087 & 0.238 & 0.021 \\
\hline
\end{tabular}

Table 7. Final calculation of emitter coefficients when three criteria are considered 


\section{AN AVAILABLE SOFTWARE TOOL}

Undertaking the iterative leakage calibration process in practical cases with only the help of EPANET and several other software tools (databases and spreadsheets) may involve a significant amount of cumbersome and tedious work for engineers or utility staff. The authors have often applied the methodology presented above by means of case-specific programming combined with the EPANET Toolkit. The authors eventually decided to prepare one general application, and like EPANET, make it freely available on the web. At the moment, a beta version of the application has been released and can be downloaded from http://efficient.ita.upv.es/downloads/Instal_ITAfugas.zip.

\section{CONCLUSION}

This paper presents a method to assist modellers in the task of simulating leakage in water distribution networks. The advantages of this method are that it enables a spatial distribution of leakage throughout the network and the adaptation of EPANET's use of emitters (mainly intended for nozzles or sprinklers) for modelling leakage in a hydraulically consistent manner. Furthermore, the spatial distribution is flexible enough to take into account and combine different leakage factors that the modeller may find relevant in the network and in the manner considered most adequate. The calibration of the emitter coefficients is solved using a straightforward iterative method and a software tool is provided as an additional aid.

\section{ACKNOWLEDGMENT}

The authors wish to thank the reviewers for their accurate comments and suggestions, which have definitely contributed to improving the paper.

\section{REFERENCES}

Al-Ghamdi, A. S. (2011). Leakage-pressure relationship and leakage detection in intermittent water distribution systems. Journal of Water Supply: Research and Technology-AQUA. 60(3). 178-183.

Almandoz J., Cabrera E., Arregui F., Cabrera Jr. E. and Cobacho R. (2005). Leakage Assessment through Water Distribution Network Simulation. Journal of Water Resources, Planning and Management, 131(6) 458466.

Ameyaw E. E.; Memon F. A. and Bicik J. (2013). Improving equity in intermittent water supply systems. Journal of Water Supply: Research and Technology-AQUA. 62(8). 552-562

Arunkumar, M. and Nethaji Mariappan, V.E (2011). Water demand analysis of municipal water supply using EPANET software. International Journal on Applied Bioengineering, 5 (1)

Berardi, L., Savic, D.A. and Giustolisi, O. (2005). Investigation of burst-prediction formulas for water distribution systems by evolutionary computing. Computer and Control in Water Industry (CCWI), Vol.2, 275-280.

Boulos P.F. and Bros C.M. (2010). Assessing the carbon footprint of water supply and distribution systems. Journal AWWA, 102(11), 47-54.

Cabrera E., Pardo M.A., Cobacho R. and Cabrera Jr. E. (2010). Energy Audit of water networks. Journal of Water Resources, Planning and Management, 136(6), 669-667

Cabrera Jr, E.; Cobacho, R.; Estruch, V. and Aznar J. (2011). Analytical hierarchical process (AHP) as a decision support tool in water resources management. Journal of Water Supply: Research and Technology-AQUA, 60(6)

Cassa, A.M. and van Zyl J, E (2013). Predicting the head-leakage slope of cracks in pipes subject to elastic deformations. Journal of Water Supply: Research and Technology-AQUA. 62(4) 214-223

Cavallo .A; Di Nardo, A; De Maria, G di Maria and Di Natale. (2013). Automated fuzzy decision and control system for reservoir management. Journal of Water Supply: Research and Technology-AQUA. 62(4) 189-204 
Colombo, A.F. and Karney, B.W. (2002). Energy and costs of leaky pipes: Toward a comprehensive Picture. J. Water Resour. Plan. Manage. 128(6), 441-450.

EPA (2013). EPANET: Software that models the Hydraulic and Water Quality Behavior of Water Distribution Piping Systems. http://www.epa.gov/nrmrl/wswrd/dw/epanet.html

García, A.; Guillem, S.; Martínez, F. and Jiménez, MA. (2012). Random scenarios generation with minimun energy consumption model for sectoring optimization in pressurized irrigation networks using a simulated annealing approach. Journal of Irrigation and Drainage Engineering. 138(7):613-624

Germanopoulos, G. (1985). A technical note on the inclusion of pressure dependent demand and leakage terms in water supply network models. Civil Engineering Systems, 2 (September), 171-179.

Germanopoulos, G. and Jowitt, P.W. (1989). Leakage reduction by excessive pressure minimization in a water supply network. Proc., Instn. Civ. Engrs., Part 2, 87(June), 195-214.

Giustolisi, O.; Savic, D. and Kapelan, Z. (2008). Pressure-driven demand and lakage simulation for water distribution networks. J. Hydraulic Engineering ASCE, 135 (5), 626-635.

Hernández, E.; Pardo, M.A.; Cabrera, E. and Cobacho, R. (2010). Energy assessment of water networks, a case study. Water Distribution System Analysis 2010 - WDSA2010, Tucson, AZ, USA, Sept. 12-15, 2010

Islam, M.S; Sadiq, R.; Rodriguez, M. J; Francisque, A; Najjaran, H.; Naser, B. and Hoorfar, M. (2012). Evaluating leakage potential in water distribution systems: a fuzzy-based methodology. Journal of Water Supply: Research and Technology-AQUA. 61 (4). 240-252

Kleiner, Y. and Rajani, B.B. (2002). Forecasting Variations and Trends in Water-Main Breaks. J. Infrastr. Sys., $8(4), 122-131$.

Lambert A., Myers S. and Trow S. (1998). Managing Water Leakage. Financial Times Business Ltd. London.

Lambert A. and Hirner W. (2000). Losses from Water Supply Systems: Standard Terminology and Recommended Performance Measures. IWA http://www.iwahq.org/1ny/themes/managing-utilities/utility-efficiency/non-revenue-water.html

May, J. (1994). Pressure dependent leakage. World Water \& Environmental Engineering Management, October.

Parra, C.; Cobacho, R. and Cabrera Jr, E. (2013). Assessment of service and structural conditions of water supply and wastewater pipes by fuzzy logic and decision space analysis. $5^{\text {th }}$ IWA International Conference on Benchmarking and Performance Assessment of Water Services. Medellin (Colombia). 912 April 2013.

Thornton J. and Lambert A. (2005). Progress in practical prediction of pressure: leakage. pressure: burst frequency and pressure: consumption relationships. In: IWA Specialized Conference Leakage 2005. Halifax. Nova Scotia. Canada. 12-14 Sept. 2005.

Triantaphyllou, E. (2002). Multi-Criteria Decision Making Methods: A Comparative Study. Kluwer Publishers Logo Kluwer Academic Publishers Applied Optimization Series, Vol. 44 ISBN 0-7923-6607-7

Todini, E. and Pilati, S. (1988). A gradient algorithm for the analysis of pipe networks. Computer Applications in Water Supply B. Coulbeck and C.H. Orr (eds), Vo.1 (System analysis and simulation), John Wiley \& Sons, London, 1-20.

Shamir, U., and Howard, C.D.D., (1979). An analytic approach to scheduling pipe replacement. J. Am. Water Works Assn., 117(5), 248-258.

Walski, T.M. and Pelliccia, A. (1982). Economics analysis of water main breaks. J. Am. Water Works Assn., 74(3), 140-147.

Walski, T.M. and Draus, S.J. (1995). An Evaluation of Water Quality at Fort Monmouth, New Jersey, Using the EPANET Model. US Army Corps of Engineers. Waterways Experiment Station. Miscellaneous Paper EL-95-6. 